\title{
Assessment of Quality of Life in Migraine
} Migrende Yaşam Kalitesinin Değerlendirilmesi

\author{
Özlem TAŞKAPILIOĞLU, Necdet KARLI \\ Uludağ University, Medical Faculty, Department of Neurology, Bursa, Turkey
}

\begin{abstract}
Quality of life is the perception of an individual's position in life associated with his objectives, expectations, interests, and standard's of life. Health-related quality of life, on the other hand, includes satisfaction with his health and emotional reaction to his state of health. Primary headaches are encountered commonly in adults during their most productive years like end of puberty and at the beginning of 50 's. Migraine alone is responsible for $1.3 \%$ of years with disability in the world, all headaches together being responsible for twice of this load. Headaches both worsen quality of life of individuals and place a significant burden on the society. This review will focus on the effects of primary headaches, especially migraine, on quality of life and tools used to evaluate these effects. (Archives of Neuropsychiatry 2013; 50 Supplement 1: S60-S64)
\end{abstract}

Key words: Headache, migraine, quality of life

Conflict of interest: The authors reported no conflict of interest related to this article.

\section{Özet}

Yaşam kalitesi, kişinin kültür ve değerler sistemi içinde amaç, beklenti, ilgi alanı ve standartları ile iliş̧i olarak yaşamda bulunduğu yeri algılama şeklidir. Sağlıkla ilişkili yaşam kalitesi ise kişinin sağllk durumundan memnuniyetini ve sağlık durumuna verdiği duygusal yanıtı içerir. Primer başağrıları, erişkinlerin en üretken olduğu ergenlik sonu ve 50'li yaşların başı arasında sıkça karşılaşılan durumlardır. Tüm dünyada özürlülükle geçen yılların \%1.3'ünden tek başına migren, bu yükün yaklaşık iki katından da tüm BA hastalıkları hep beraber sorumludur. Başağrısı hem kișinin yaşam kalitesini bozmakta hem de topluma ciddi maddi yük getirmektedir. Bu derlemede, hastalık yükünün primer başağrısının, özellikle migrenin, kişinin yaşam kalitesi üzerine etkisi ve bunun değerlendirilmesinde kullanılan ölçütler gözden geçirilecektir. (Nöropsikiyatri Arşivi 2013; 50 Özel Sayı 1: S60-S64)

Anahtar kelimeler: Başağrısı, migren, yaşam kalitesi

Çıkar çatışması: Yazarlar bu makale ile ilgili olarak herhangi bir çıkar çatışması bildirmemişlerdir.

his/her objectives, expectations, areas of interest and standards within his/her culture and fundemental values. The determinants of quality of life include the health, occupation, shelter, education and environment of the individual. The complex effect of culture, values and beliefs on the quality of life makes its measurement difficult. Investigators have developed tools to help us understand and measure these different areas and their relations with each other.

Health-related quality of life constitutes only one part of quality of life. It includes the individual's satisfaction with his/her health status and emotional response he/she gives to his/her health status. It has been developing since 1960 s such as to cover all determinants (physical and mental) which have been shown to affect the health status $(3,4,5,6,7)$.

Healt related quality of life includes individual physical and mental healt concept and relations (conditions which jeopardize Quality of life is the way of perception of an individual in relation with 
health, functional status, social support, socioeconomical status) as well as a community's perception of health and sources, conditions, politics and applications affecting its functional status. Measurement of health status and determination of the efficiency of healthcare service should not only include the changes in the frequency and severity of morbidities, but also show the improvement in healt related quality of life. Standardized criteria related with health-related quality of life help to evaluate the developments in reaching public health objectives, health-related incompatibilities in different groups of the population and the efficiency of addressing age-related diseases $(8,9,10,11)$.

Almost half of the adult population in the world complain one or more types of headache (HA)at least for one time for a life time. Although it shows variance according to different areas ofthe world, migraine, tension $\mathrm{HA}$ and medication overuse $\mathrm{HA}$ are among the most common diseases of the human being. Prevalance studies show that $-3 / 4$ of the adult population between the ages of 18 and 65 years have experienced $\mathrm{HA}$ in the last one year. Migraine is observed in $11 \%$ of the adults worldwide and affects women 3 fold more frequently compared to men. 1.7-4\% of the adult population experience HA for 15 days a month or more frequently. Based on the figures related with migraine prevalence and the incidence of attacks, it is calculated that $\mathbf{3 0 0 0}$ migraine attacks are experienced each day per one million of the generalpopulation. The study entitled "Global Disease Burden" updated by the WHO in 2004 showed that migraine was responsible alone of $1.3 \%$ of the years with disability and the remaining $\mathrm{HAs}$ were responsible of a similar burden all together $(12,13,14)$.

The complete burden of headache in terms of public health is not known. Despite this, a great portion of the patients can not receive efficient medical treatment because of limited resources allocated by countries to $\mathrm{HA}$. The WHO who colloborated with a campaign which was related w,th eliminating the burden ("Lifting the Burden") and was conducted in the whole world published the $\mathrm{HA}$ atlas in $2011(15,16,17)$. The information included here was obtained by way of a questionnaire applied to neurologists, general practitioners and patients representing 101 countries between November 2006 and March 2009. In only 18\% of the countries included in these surveys, information about the social burden due to HA could be reached. IN 12\% of the countries included in the surveys, HA was used in in the yearly health reporting system and in only 7\% $\mathrm{HA}$ was used in calculation of the gross national product (14).

Primary headaches are observed frequently in the period between the end of adolescence and the begining of mid-fifties during which adults have the maximum productivity. Neurological diseases are responsible of $3 \%$ of the years with disability in the whole world and migraine is responsible of $1 / 3$ of this (18). Recurrent $\mathrm{HA}$ attacks and frequently persistent fear and concern about the next attack disrupt the individual's familial, occupational and social life. The individual cancels his/her social activities and confronts with labeling as an "unreliable-not to be working together" person by his/her friends and employers beacuse of not being able to finish a work due to an unexpected attack or not being able to show the expected performance at a very significant time. This decreases the possbility of advancing in the career and reduces his/her expectation about career and financial future. In addition to the burden on the individual who experiences HA, his/her employers, co-workers, family and friends in his/her private life take their share from the individuals lost working hours and reduced productivity.

Although there is no mortality related with primary HAs, the experience of pain of the patient with $\mathrm{HA}$, both disrupts the quality of life and puts a severe financial burden on the community. In this review, the effect of primary HA diseases on the quality of life of the individual will be reviewed, but not the disease burden on the community.

A screening in medline by giving the key words "migraine" and "quality of life" will show how the interest on this issue has increased since 1990s. In 2001, Andresik, stated that he detected 63 subscales which did not intersect with each other to measure the effect of migraine on the quality of life and recommended to determine the areas which relate these subscales with each other instead of developing more scales (19). There are 70 articles published between 2010 and 2012 which adressed health-related quality of life and /or disability as primary and secondary end points in adult patients with primary HA. Analysis of 12 of these showed that health-related quality of life and disability as well as HA frequency were afffected positivley by treatment approaches, similar results were obtained in two observational studies and SF36 was sensitive in displaying the temporal change in quality of life and functions in HA patients similar to disease-specific tools (20).

The methods to be used in measurement of health-related quality of life have been defined for many morbidities (21).

I. Criteris assessing the general health status: General quality of life questionnaires include Brief Form-36 and its shortened forms $(22,23,24,25,26,27,28,29)$, European Quality of Life Scale (30), Disease Impact Profile (31) and its shortened form); Health Utilities Index (HUI) (33), Well-Being Scale $(34,35)$, Notthingham Health Profile (NHP) $(36,37,38,39)$, Patient Generated Index (40), Quality of Life Assessment Tool -100 (WHOQOL-100) (41) and WHO Quality of Life Assessment Tool Brief Form (WHOQOLBREF) (42), Quality of Life Index (43), Life Satisfaction Index (44), (World Health Organization Disability Assessment Schedule, second version, WHO-DAS II) (45).

These questionnaires provide comparison between different diseases; they are not specific for accompanying diseases. Their most important limitation is the fact that they are very long. However, brief forms have been developed for some questionnaires later and their use in large researches and clinical studies has been facilitated.

SF-36: It is most commonly used in medicine. 8 subscales containing 36 items provide assessemtn of the individual in terms of physical and cognitive status. Its adaptation for the Turkish population was performed (23). Its disadvantages include inability to assess the areas including sleep, cognitive function, sexual function, communication and recreation, insensivity to the cognitive dimension of subjective well-being while being sensitive to the emotional dimension and presence of ceiling and floor effect (25).

Short form 36 (SF-36) is a questionnaire which assesses the effect of disease in 8 dimensions of health (physical function, rol limitation related with physical problems, body pain, general health perception, vitality, social function, role loss due to emotional problems and mental health). For each subscale a score of 0-100 is obtained. A higher score shows a better quality of life (24). When it was developed initially, a change of 5 points in the general health scale was stated to be minimal clinically important difference (MCID) (24). However, the studies conducted later showed that changes of 3-5 points could be significant, but it should be carefully examined if the differences were significant or not $(25,26,27,28,29)$

European Quality of Life-5 Dimensions(EQ-5D) scale was developed bytheEuroQolgroup(WestEuropeQuality of Life Research Association) in 1987. It was translated to more than 60 languages 
including Turkish. It is composed of five dimensions/movement, self-care, ordinary activities, pain/discomfort, anxiety/depression) where the individual reports his/her own status himself/herself $(30$, $46,47,48,49,50)$. For each dimension one answer is given among three options (no problem, some problems are present and major problem). With this scale 243 possible different health results are defined. The index score ranging between -0.59 and 1 from the 5 dimensions of the scale is calculated by using the coefficients produced by Dolan et al.. A value of 0 indicates mortality and a value of 1 indicates perfect health, while negative values indicate conditions including loss of consciousness and bed-ridden status. Instant healt states of individuals are measured by marking one of the values between 0 and 100 on the visual analog scale (VAS); a score of 100 represents the best status. It is used in assessing the effect of different morbidities including psychiatric diseases, other medical conditions and surgical operations on quality of life $(30,46$, $47,48,49)$.

Disease Impact Profile assesses the health status in 12 areas (ambulation, mobility, body care and movement, communication, attention, emotional status, social integration, sleep and rest, nutrition, house-related activities, occupational status, hobbies and recreation) with 136 items. The whole scale may be used or its parts may be used seperately. SIP68 is a short form containing 68 items. Its disadvantages include its lenght and absence of an area of pain $(31,32)$.

Notthingham Health Profile: This is a scale which aims to assess the physical, emotional and social health status perceived by the individual himself/herself . It has a Turkish version $(36,37$, 38,39 ). It is composed of two parts : The frequently used part is the first part composed of 38 items and assesses quality of life in 6 areas (sleep status, energy level, emotional status, social isolation status, physical mobility and pain). The second part is applied in appropriate patients and assesses the areas including gainful occupation, Works related with house, social life, sexual life, hobbies and areas of interest and vacation life.

An inter-cultural validity study of the WHO Disability Assessement Schedule was performed in 17 countries including Turkey to understand the differences in the language and concepts used while describing disability and the community's response to this (37). This tool is a semi-structured interview scale composed of 36 items. It tries to determine how much difficulty the individual has experienced while performing certain activities in the last one month. The titles of 6 activities are as follows: 1) Understanding and communication, 2) Movement and going from one place to another, 3) Self-care, 4) Human relations, 5) Life activities, 6) Participation in the cial life. The answers given to all these areas as none, some, moderate, much, excessively/never are scored between 1 and 5. WHO-DAS-II has been prepared to assess individuals above the age of 18 years who are different in terms of education level, cultural properties and cognitive abilities. The patient needs not to be literate. For a standard interview, the interviewers who will as the questions and record the data should be educated. The interviewer should ensure that the patient has understood the questions and give the necessary explanations, when the patient does not understand or misunderstand the questions. The application last for approximately 20 minutes (45).

II. Disease-specific criteria: Disease-specific quality of life scales developed for migraine include MIDAS (Migraine disability Assessment Scale) (50, 51), 24 h MQoLQ (24-hour Migraine Quality of Life Scale) (52), Migraine-Specific Quality of Life QuestionnaireMSQ $(53,54,55,56,57,58)$ and Headache Requirement Assessement Scale (59). The reliability and validity of the first two scales for the
Turkish population was examined. The others are migraine-specific health quality scales, but their reliability and validity for the Turkish population have not been studied yet.

Since disease-specific questionnaires are more sensitive compared to general quality of life questionnaires, they do not overlook differences or changes which are significant in terms of that disease.

(1) Migraine-specific Quality of Life questionnaire version 2.1 (MSYK v2.1)

MSYK v2.1 is composed of 14 questions which assess the limitations in daily performance because of migraine (54). It is composed of three areas including restrictive role, preventive role and emotional function. The first two areas reach the data related with decrease in and prevention of daily social and occupational activities, while the last area assesses the emotions related with migraine. The scores corresponding to the answer given to each question are summed and a value is obtained. Higher scores indicate a better health-related quality of life.

When we examine the studies in the literature related with both general and migraine-specific quality of life scales, the following picture is confronted:

It was shown that EYK-5D scores became worse compared to the period without attack, when frequent attacks were experienced in patients with migraine (64). When the service utility values of EQ-5D scores of 106 patients with migraine were evaluated, it was found that utility was significantly low in all migraine pain degrees, as the severity of migraine increased, utility decreased, severe migraine pain was described as "worse than death" and these results could be used in utility cost models in which the economical values related with migrain treatment are examined (65).

SF-36 has been used frequently in painful states as well as in studies conducted with patients with migraine $(60,61,64,65)$. The studies in which both SF36 and its short form SF12 have been used have showed that the quality of life is worse in patients with migraine compared to both the general population and patients with otherchronic diseases. The greatest reductions in scores in patients with migraine were observed in the areas related with role limitation, social function and body pain (61). In addition, the reduction in scores in patients with chronic migraine is extensive including more subscales. Improvement in pain and psychological well-being scales are the most beneficial scores to predict improvement in SF-36. Another study which aimed to elucidate the effects of pain and depression on the quality of life in migraine showed that the risk of experiencing extensive chronic pain in women with migraine increased depending on the frequency of HA and both depressive symptoms and chronic migraine could predict the quality of life independent of other factors (62). These results indicate the importance of diagnosis and treatment of comorbid psychiatric diseases during treatment of $\mathrm{HA}$.

Studies have shown that migraine affected the individual's daily life and quality of life negatively, the frequency, severity, accompanying symptoms including nausea, phonophobia and photophobia of migraine and comorbid conditions including mood disorders contributed to this negativity and pain was sufficient to disrupt the quality of life by itself independent of accompanying factors $(63,64,65,66,67,68)$.

While the difference in quality of life between patients with migraine and other episodic HAs has been assessed using SF-36 in many studies, fewer studies have used SF-36 in chronic daily HA. It was found that the scores of the patients with chronic daily HA were lower in most areas of SF-36 compared to healthy controls and this was especially more prominent in the areas of physical 
role and body pain. It was observed the scores of the patients with chronic daily HA were worse in most areas of SF-36 compared to the patients with episodic $\mathrm{HA}$ and this was especially more prominent in the areas of general health, vitality and emotional role. In all the studies except for one study, SF-36 quality of life scores were found to be lower in patients with chronic daily headache carrying migraine-like characteristics compared to patients with chronic daily headache who do not carry migraine-like characteristics. Again, in most studies, SF-36 quality of life scores in patients with chronic daily headache with medication overuse were found to be lower compared to patients with chronic daily headache without medication overuse. According to MIDAS assessments, it was found that disability and productivity were affected with a higher rate in patients with chronic daily headache compared to patients with episodic headache (69).

In studies performed in Spain and France, it was shown that the quality of life was worse in patients with chronic daily headache compared to patients with episodic migraine. Similar SF scores were found in patients in HA clinics (61). Two studies performed in Taiwan and USA $(60,70)$ showed that the quality of life was worse in patients with transformed HA who presented to HA clinics compared to patients with episodic migraine.

Another area in which the assessment of quality of life is used includes studies aimed to display drug efficiency. It was shown that improvement occured in health-related quality of life measured using both general and disease-specific scales in patients treated with sumatriptan $(71,72,73)$. According to the results of the 24-hour migraine-specific quality of life questionnaire, the quality of life of the patients who used $10 \mathrm{mg}$ rizatriptan was better compared to the placebo group (74). In a study in which the effect of acute migraine attack treatment on migraine-specific quality of life in the short-term was examined, complete and persistent pain control after treatment and achievement of normal function in the second hour of treatment caused to a better short-term health-related quality of life (75).

When determining the effect of migraine on health-related quality of life, it was a problem notbeing able to show the counterpart (77) in the perspective of the "International Classification of Functioning, Disability and Health" (ICF) (76). In a study performed in Italy to demonstrate the relation between health-related quality of life and disability in the biopsychosocial model defined in ICF, a general new tool was used (World Health Organization Disability Assessment Schedule, second version WHO-DAS II) (45). In this study, the relation between MIDAS and WHO-DAS II was also examined. At the end of the study, it was reported that health-related quality of life and WHO-DAS II examined different psychosocial aspects of migraine, researchers should use both in their studies, because migraine affects the individual's functionality to a great extent apart from its economical burden (78).

In the last 20 years, the importance of disease burden and awareness of the effect of treatment options on the health status of patients have increased. It is observed that these are measured using objective criteria in clinical studies. These criteria provide significant information in the preferance of treatment options and in development of optimal treatment algorithms. Development of these criteria in the area of migraine and demonstration of their reliability have provided perception of migraine by the patient's eye. The data related with the quality of life of patients with HA who are confronted widely will be beneficial in development of better treatment approaches and management methods by providing treatment satisfaction and determination of individual requirements.

\section{Kaynaklar}

1. Constitution of the World Health Organization. Geneva: World Health Organization; 1948. http://www.opbw.org/int_inst/health_docs/WHO-CONSTITUTION.pdf.

2. The WHOQOL Group. The World Health Organization Quality of Life Assessment (WHOQOL). Development and psychometric properties. Soc Sci Med 1998; 46:1569-1585.

3. McHorney CA. Health status assessment methods for adults: past accomplishments and future directions. Annual Rev Public Health 1999; 20:309-335.

4. Calvert MJ, Freemantle N. Use of health-related quality of lif in prescribing research. Part 1: why evaluate health-related quality of life? J Clin Pharm Ther 2003; 28:513-521.

5. Gandek B, Sinclair SJ, Kosinski M, Ware JE Jr. Psychometric evaluation of the SF-36 health survey in Medicare managed care. Health Care Financ Rev 2004; 25:5-25

6. Centers for Disease Control and Prevention. Measuring healthy days: Population assessment of health-related quality of life. Centers for Disease Control and Prevention. Atlanta; Georgia; 2000.

7. Selim AJ, Rogers W, Fleishman JA, Qian SX, Fincke BG, Rothendler JA Kazis LE. Updated U.S. population standard for the Veterans RAND 12-item Health Survey (VR-12). Qual Life Res 2009; 18:43-52.

8. Hennessy CH, Moriarty DG, Zack MM, Scherr PA, Brackbill R. Measuring health-related quality of life for public health surveillance. Public Health Rep 1994; 109:665-672.

9. Dominick KL, Ahern FM, Gold CH, Heller DA. Relationship of health-related quality of life to health care utilization and mortality among older adults. Aging Clin Exp Res 2002; 14:499-508.

10. DeSalvo KB, Bloser N, Reynolds K, He J, Muntner P. J. Mortality prediction with a single general self-rated health question. A meta-analysis. Gen Intern Med 2006; 21:267-275.

11. Kindig DA, Booske BC, Remington PL. Mobilizing Action Toward Community Health (MATCH): metrics, incentives, and partnerships for population health. Prev Chronic Dis 2010; 7:68.

12. Leonardi M, Steiner TJ, Scher AT, Lipton RB. The global burden of migraine: measuring disability in headache disorders with WHO's Classification of Functioning, Disability and Health (ICF). J Headache Pain 2005; 6:429-440.

13. Stovner Lj, Hagen K, Jensen R, Katsarava Z, Lipton R, Scher A, Steiner T, Zwart JA. The global burden of headache: a documentation of headache prevalence and disability worldwide. Cephalalgia 2007; 27:193-210.

14. WHO. Atlas of headache disorders and resources in the world. Geneva: 2011

15. Steiner TJ. Lifting the burden: the global campaign against headache Lancet Neurol 2004; 3:204-205.

16. Steiner TJ. Lifting The Burden: the global campaign to reduce the burden of headache worldwide. J Headache Pain 2005; 6:373-377.

17. Steiner TJ, Birbeck GL, Jensen R, Katsarava Z, Martelletti P, Stovner LJ. Lifting the burden: the first 7 years. J Headache Pain 2010; 11:451-455.

18. Vos T, Flaxman AD, Naghavi M, Lozano R, Michaud C, Ezzati M, Shibuya K, Salomon JA, Abdalla S, Aboyans V, Abraham J, Ackerman I, Aggarwal R, Ahn SY, Ali MK, Alvarado M, Anderson HR, Anderson LM, Andrews KG, Atkinson C, Baddour LM, Bahalim AN, Barker-Collo S, Barrero LH, Bartels DH, Basáñez MG, Baxter A, Bell ML, Benjamin EJ, Bennett D Years lived with disability (YLD) for 1160 sequelae of 289 diseases and injuries 19902010: a systematic analysis for the Global Burden of Disease Study Lancet 2010; 380:2163-2196.

19. Andresik F. Migraine and quality of life: psychological considerations. J Headache Pain 2001; 2:1-9.

20. D'Amico D, Grazzi L, Usai S, Leonardi M, Raggi A. Disability and quality of life in headache: where we are now and where we are heading. Neurol Sci 2013; 34(Suppl 1):1-5.

21. Guyatt GH, Bombardier C, Tugwell PX. Measuring disease-specific quality of life in clinical trials. Can Med Assoc J 1986; 134:889-895.

22. Brazier JE, Harper $R$, Jones NM, O'Cathain A, Thomas KJ, Usherwood T, Westlake L. Validating the SF-36 health survey questionnaire: new outcome measure for primary care. Br Med J 1992; 305:160-164.

23. Ware Jr JE, Sherbourne CD. The MOS 36-item short-form health survey (SF-36), I: conceptual framework and item selection. Medical Care 1992; 30:473-483. 
24. McHorney CA, Ware JE Jr, Raczek AE. The MOS 36-Item Short-Form Health Survey(SF-36): II. Psychometric and clinical tests of validity in measuring physical and mental health constructs. Med Care 1993; 31:247263.

25. Angst F, Aeschlimann A, Stucki G. Smallest detectable and minimal clinically important differences of rehabilitation intervention with their implications for required sample sizes using WOMAC and SF-36 quality of life measurement instruments in patients with osteoarthritis of the lower extremities. Arthritis and Rheumatism 2001; 45:384-391.

26. Hays RD, Morales LS. The RAND-36 measure of health-related quality of life. Annals of Medicine 2001; 33:350-357.

27. Hays RD, Hahn H, Marshall G. Use of SF-36 and other health-related quality of life measures to assess persons with disabilities. Arch Phys Med Rehabil 2002; 83(Suppl 2):4-9.

28. Andresen EM, Meyers AR. Health-related quality of life outcomes measures. Arch Phys Med Rehabil 2000; 81(Suppl 2):30-45.

29. Koçyiğit H, Aydemir Ö, Fişek G, Ölmez N, Memis A. Kısa Form-36 (KF-36)'nin Türkçe versiyonunun güvenilirliği ve geçerliliği. Romatizmal hastalığı olan bir grup hasta ile çalışma. İlaç ve Tedavi Dergisi 1999; 12:102-106

30. Rabin R, de Charro F. EQ-5D: a measure of health status from the EuroQol Group. Ann Med 2001: 33:337-343.

31. Bergner M, Bobbitt RA, Carter WB, Gilson BS. The Sickness Impact Profile: Development and final revision of a health status measure. Med Care 1981; 19:787-805.

32. de Bruin AF, Diederiks JPM, de Witte LP, Stevens FCJ, Philipsen H. The development of a short generic version of the Sickness Impact Profile. J Clin Epidemiol 1994: 47:407-418.

33. Furlong WJ, Feeny DH, Torrance GW, Barr RD. The Health Utilities Index (HUI_) system for assessing health-related quality of life in clinical studies. Ann Med 2001; 33:375-384.

34. Kaplan RM, Sieber WJ, and Ganiats TG. The quality of well-being scale: Comparison of the interviewer- administered version with a selfadministered questionnaire. Psych Health 1997; 12:783-791.

35. Sieber WJ, David KM, Adams JE, Kaplan RM, Ganiats TG. Assessing the impact of migraine on health-related quality of life: An additional use of the quality of well-being scale-self-administered. Headache 2000; 40:662-671.

36. Hunt SM, McKenna SP, McEwen J, Backett EM, Williams J, Papp E. A quantitative approach to perceived health status: a validation study. $\mathrm{J}$ Epidemiol Community Health 1980; 34:281-286.

37. Hunt S, McKenna S, McEwan J, Williams J, Papp E. Nottingham Health Profile: subjective health status and medical consultation. Soc Sci Med 1981; $15: 221-229$.

38. Hunt S, McKenna S, Williams J. Reliability of a population survey tool for measuring perceived health problems: a study of patients with osteoarthritis J Epidemiol Community Health 1981:35:297-300.

39. Küçükdeveci AA, McKenna S, Kutlay S, Gürsel Y, Whalley D, Arasıl T. The development and psychometric assessment of the Turkish version of the Nottingham Health Profile. Int J Rehabil Res 2000; 23:31-8.

40. Ruta DA, Garratt AM, Leng M, Russell IT, MacDonald LM. A new approach to the measurement of quality of life: the patient generated index (PGI). Med Care 1994; 32:1109-1126.

41. Power $M$, Harper $A$, Bullinger $M$. The World Health Organization WHO0OL-100: tests of the universality of Quality of Life in 15 different cultural groups worldwide. Health Psychol 1999; 18:495-505.

42. Development of the World Health Organization WHOOOL-BREF quality of life assessment. The WHOOOL Group. Psychol Med 1998; 28:551-558.

43. Ferrans CE, Powers MJ. Psychometric assessment of the Quality of Lifelndex. Res Nurs Health 1992; 15:29-38.

44. White A. A Global Projection of Subjective Well-being: A Challenge To Positive Psychology? Psychtalk 2007; 56:17-20.

45. Garin 0, Ayuso-Mateos JL, Almansa J, Nieto M, Chatterji S, Vilagut G, Alonso J, Cieza A, Svetskova O, Burger H, Racca V, Francescutti C, Vieta E, Kostanjsek N, Raggi A, Leonardi M, Ferrer M; MHADIE consortium. Validation of the World Health Organization 'Disability Assessment Schedule (WHODAS-2) in patients with chronic diseases. Health Qual Life Outcomes 2010; 8:51

46. Xu R, Insinga RP, Golden W, Hu XH. EuroQol (EQ-5D) health utility scores for patients with migraine. Quality of Life Research 2011; 20:601-608

47. Stafford MR, Hareendran A, Ng-Mak DS, Insinga RP, Xu R, Stull DE.EQ$5 D^{\mathrm{TM}}$-derived utility values for different levels of migraine severity from a UK sample of migraineurs. Health and Quality of Life Outcomes 2012; 10:65.

48. Essink-Bot ML, Krabbe PF, Bonsel GJ, Aaronson NK. An empirical comparison of four generic health status measures. The Nottingham Health Profile, the Medical Outcomes Study 36-item Short-Form Health Survey, the COOP/-WONCA charts, and the Euro0ol instrument. Medical Care 1997; 35:522-537.

49. Post MWM, deBruin A, deWitte L, Schrijvers A. The SIP68: A measure of health-related functional status in rehabilitation medicine. Arch Phys Med Rehabil 1996; 77:440-445.

50. European Group for Quality of Life Assessment and Health Measurement: European Guide to the Nottingham Health Profile. Brookwood-Surrey, Brookwood Medical Publications, 1993.
51. StewartWF, Lipton RB, Kolodner KB, Sawyer J, Lee C, Liberman JN. Validity of the Migraine Disability Assessment (MIDAS) score in comparison to a diary-based measure in a population sample of migraine sufferers.Pain 2000; 88:41-52.

52. Hartmaier SL, Santanello NC, Epstein RS, Silberstein SD. Development of a brief 24-hour migraine-specific quality of life questionnaire. Headache 1995; 35:320-329.

53. Jhingra P, Osterhaus JT, Miller DW, Lee JT, Kirchdoerfer L. Development and validation of the Migraine-Specific Quality of Life Questionnaire. Headache 1998; 38:295-302.

54. Martin BC, Pathak DS, Sharfman MI, Adelman JU, Taylor F, Kwong WJ, Jhingran P.Validity and reliability of the Migraine-Specific Quality of Life Questionnaire (MSQ version 2.1). Headache 2000; 40:204-215.

55. Jhingran P, Davis SM, LaVange LM, Miller DW, Helms RW. MSQ: MigraineSpecific Quality-of-Life Questionnaire. Further investigation of the factor structure 152. Pharmacoeconomics 1998; 13:707-717.

56. Cole JC, Lin P, Rupnow MF. Validation of the Migraine-Specific Quality of Life Questionnaire version 2.1 (MSQ v. 2.1) for patients undergoing prophylactic migraine treatment. Quality of Life Research 2007; 16:1231-1237.

57. Cole JC, Lin P, Rupnow MF. Minimal important differences in the MigraineSpecific Quality of Life Questionnaire (MSQ) version. Cephalalgia 2009; 29:1180-1187.

58. Jhingran P, Davis SM, LaVange LM, Miller DW, Helms RW. MSQ: MigraineSpecific Quality-of-Life Questionnaire. further investigation of the factor structure. Pharmacoeconomics 1998; 13:707-717.

59. Headache Needs Assessment questionnaire)( Cramer JA, Silberstein SD, Winner P. Development and validation of the Headache Needs Assessment (HANA) survey. Headache 2001; 41:402-409.

60. Wang SJ, Fuh JL, Lu SR, Juang KD. Quality of life differs among headache diagnoses: analysis of SF-36 survey in 901 headache patients. Pain 2001 89:285-292.

61. Monzon MJ, Lainez MJ. Quality of life in migraine and chronic daily headache patients. Cephalalgia 1998; 18:638-643.

62. Stuginski-Barbosa J, Dach F, Bigal M, Speciali JG. Chronic Pain and Depression in the Quality of Life of Women With Migraine - A Controlled Study.. Headache 2012; 52:400-408.

63. Leonardi M, Steiner TJ, Scher AT, Lipton RB. The global burden of migraine: measuring disability in headache disorders with WHO's classification of Functioning, Disability and Health (ICF). J Headache Pain 2005; 6:429-440.

64. Lipton RB, Bigal ME. Migraine: epidemiology, impact, and risk factors for progression. Headache 2005; 45(Suppl 1):3-13.

65. Terwindt GM, Ferrari MD, Launer LJ. The impact of headache on quality of life. J Headache Pain 2003; 4:35-41.

66. Breslau N, Lipton RB, Stewart WF, Schultz LR, Welch KM. Comorbidity of migraine and depression: investigating potential etiology and prognosis Neurology 2003; 60:1308-1312

67. Radat F, Swendsen J. Psychiatric comorbidity in migraine: a review. Cephalalgia 2005; 25:165-178.

68. Holroyd KA, Drew JB, Cottrell CK, Romanek KM, Heh V. Impaired functioning and quality of life in severe migraine: the role of catastrophizing and associated symptoms.Cephalalgia 2007; 27:1156-1165.

69. Lante'ri-Minet Michel, Duru Ge'rard, Mudge Mia, Cottrell Suzi. Quality of life impairment, disability and economic burden associated with chronic daily headache, focusing on chronic migraine with or without medication overuse: A systematic review. Cephalalgia 2011;31:837-850.

70. Meletiche DM, Lofland JH, Young WB. Quality-of-life differences between patients with episodic and transformed migraine. Headache 2001; 41:573578

71. Solomon GD, Skobieranda FG, Genzen JR. Quality of life assessment among migraine patients treated with sumatriptan. Headache 1995; 35:449454

72. Jhingran P, Cady RK, Rubino J, Miller D, Grice RB, Gutterman DL. Improvements in health-related quality of life with sumatriptan treatment for migraine. J Fam Pract 1996; 42:36-42.

73. Mushet GR, Miller D, Clements B, Pait G, Gutterman DL. Impact of sumatriptan on workplace productivity, nonwork activities, and healthrelated quality of life among hospital employees with migraine. Headache 1996; 36:137-143

74. Santanello NC, Polis AB, Hartmaier SL, Kramer MS,Block GA Silberstein SD. Improvement in migraine-specific quality of life in a clinical trial of rizatriptan. Cephalalgia 1997; 17:867-872.

75. Santanello NC, Determinants of migraine-specific quality of life. Cephalalgia 2002; 22:680-685

76. World Health Organization. The International Classification of Functioning Disability and Health-ICF. Geneva: WHO; 2001

77. Leonardi M, Bickenbach J, Ustun TB,Kostanjsek N. Chatterji S, on behalf of the MHADIE consortium. The definition of disability: What is in a name? Lancet 2006; 368:1219-1221.

78. Leonardi M, Raggi A, Bussone G, D'Amico D. Health-Related Quality of Life, Disability and Severity of Disease in Patients With Migraine Attending to a Specialty Headache Center. Headache 2010; 50:1576-1586. 